\title{
Optimization and statistical modeling of microbial cellulase production using submerged culture
}

\author{
Pratibha Maravi, Anil Kumar* \\ School of Biotechnology, Devi Ahilya University, Indore, Madhya Pradesh, India.
}

ARTICLE INFO

Article history:

Received on: October 05, 2020

Accepted on: November 28, 2020

Available online: March 10, 2021

\section{Key words:}

Bacillus licheniformis,

Cellulase,

Central composite design,

Ochrobactrum anthropi,

Optimization,

Response surface methodology,

Second order polynomial model,

Statistical experimental design.

\section{ABSTRACT}

Cellulase is considered to be much important enzyme in organic acid and biotechnology industries. Earlier, we have isolated cellulase producing two different bacterial strains from soils collected from a paper manufacturing plant, Budhar, Central India, and from a grass and forage store present nearby Hotel Radisson Blu, Indore, and after biochemical, physical, and physiological characterization including 16S rRNA sequencing, confirmed as Bacillus licheniformis Bi1 and Ochrobactrum anthropi Oa2, respectively. Here, in this study, we optimized four variables, namely, incubation period, temperature, $\mathrm{pH}$, and inoculum percentage for cellulase production medium to get maximum cellulase production using statistical experimental design, Central Composite Design and further refined using the statistical second order polynomial model, Response Surface Methodology (RSM). Under optimized conditions, cellulase activity produced was $118 \pm 12 \mu \mathrm{M} / \mathrm{min} / \mathrm{mg}$ and $69.3 \pm 8.5 \mu \mathrm{M} / \mathrm{min} / \mathrm{mg}$, respectively, whereas predicted value was $124 \mu \mathrm{M} / \mathrm{min} / \mathrm{mg}$ and $82.3 \mu \mathrm{M} / \mathrm{min} / \mathrm{mg}$ for $B$. licheniformis Bi1 and $O$. anthropi Oa2, respectively. There was 2.5 -fold increase in production of cellulase by applying RSM model.

\section{INTRODUCTION}

The $\beta-1,4$ glucan is a vital component of a plants cell wall and is considered to be the plentiful polysaccharide in plants and is synthesized by photosynthesis [1]. It, also commonly called as cellulose, is an unsolvable water polymer comprised of repeated units $\beta$-D-glucopyranose closely intertwined through $\beta$ - 1,4 glucoside linkages [2]. Main emphasis is being given to build sustainable structures for the coherent application of cellulosic leaving residuals that are used for the cost effective production of cellulase. The employment of different cellulase producing bacteria and fungi under normal atmospheric and higher temperature conditions for cellulose biotransformation into the economically important substances such as common saccharides and ethanol has gained global recognition [3].

Cellulose is generally hydrolyzed by the cellulase enzyme complex comprised of three components namely endo-1,4- $\beta$-D-glucanase (EC 3.2.1.4), exo- 1,4- $\beta$-D-glucanase (EC 3.2.1.74), and $\beta$-glucosidase (EC 3.2.1.21). The crystalline as well as amorphous paracrystalline structures of cellulose are hydrolyzed by endoglucanase. This enzyme is commonly called as cellulase. It is chiefly secreted by many microbes [4].

\section{*Corresponding Author}

Anil Kumar,

School of Biotechnology, Devi Ahilya University, Indore - 452001 ,

Madhya Pradesh, India.

E-mail: ak_sbt@yahoo.com
Bacterial cellulases have acquired much significance for degradation of cellulose at the industrial level due to rapid growth rate and genetic diversity due to broad range of genetic variability, resilient, and highly modifiable to genetic manipulation [1].

Substantial basic and applied cellulase studies have indicated high economic value and industrial applications for cellulase. It has broad array of applications in key commercial industries such as foodstuffs processing/manufacturing, paper manufacturing, medicines, fabric/clothes, bioethanol/fruits drinks, and biofuels [2]. Therefore, demand for this enzyme is increasing continuously and enormously [5]. Cellulolytic microorganisms have been isolated from soil, natural waste, gut, marine dregs, and ocean growth [6]. Cellulase production is an inducible process fundamentally affected by biochemical and physical procedure boundaries, namely, incubation period, temperature, $\mathrm{pH}$, and inoculum. Different nutritional boundaries (carbon, nitrogen, and mineral sources) and physical boundaries must be regulated/optimized to enhance catalyst efficiency and production of cellulase. The mentioned parameters seem to be extremely significant for the economy of enzyme isolation and are generally taken as the obstruction in the commercial applications of any technique. For improving the physical and concoction boundaries, one factor at a time (OFAT) approach is commonly utilized in research for optimization of enzyme production. However, OFAT takes more efforts to complete numerous parameters and the cooperation between factors could not be explained as well. To overcome these issues, factorials cum 
measurements based investigational techniques capable to deliver quick and dependable results are desired. In the present study, multi-factors analyses using statistical experimental design, Central Composite Design (CCD) and Response Surface Methodology (RSM) are carried out. The CCD is a factorial based experiment designing tool used to assess the importance of the basic factors [7], whereas, RSM is used to assess the cooperation of the autonomously operated factors like physical factors. This strategy utilizes a factual trial structure and gives measurably approved expectations to facilitate the production of cellulase $[8,9]$. The present study was carried out to upgrade economically efficient cellulase production from cellulase producing bacteria, Bacillus sp. and Ochrobactrum sp. earlier identified by us.

\section{MATERIALS AND METHODS}

\subsection{Isolation and Identification of Cellulase Producing Microorganism}

Isolation of Bacillus licheniformis $\mathrm{Bi1}$ and Ochrobactrum anthropi $\mathrm{Oa} 2$ was carried out as described earlier [10]. Bacterial cultures were isolated from five different soil samples collected from different sites considered to be enriched in cellulase producing bacteria as described earlier [10]. The soil samples were $100 \times$ serially diluted with $0.90 \%$ sodium chloride solution. Thereafter, these were used as inocula for sterile inoculations on carboxymethyl cellulose (CMC) agar petri-plates. The composition of the medium was carboxymethylcellulose $(0.5 \%)$, sodium nitrate $(0.1 \%)$ dipotassium hydrogen phosphate $(0.1 \%)$ potassium chloride $(0.1 \%)$, magnesium sulfate $(0.05 \%)$ yeast extract $(0.05 \%)$, and agaragar (1.5\%), $\mathrm{pH}$ adjusted to 7.0 using a $\mathrm{pH}$ meter. After inoculation, petri-plates were incubated at $37^{\circ} \mathrm{C}$ for $48 \mathrm{~h}$. From the grown bacterial colonies, replica plates were prepared, and thereafter, Congo red dye was spread for primarily detecting cellulase secreting bacteria by plate assay method. The largest clear zone around the colony was considered as a potential isolate for secreting cellulase enzyme. The positive results exhibiting bacterial colonies were used to inoculate the liquid medium with CMC (1\%) and were allowed to grow in an environmental orbital shaker at $150 \mathrm{rpm}$ speed for testing cellulase secretion. Biochemical as well as molecular characterization has been described earlier [10].

\subsection{Cellulase Assay and Protein Estimation}

The enzyme assay was carried out as described by Sethi et al. [11] with some modifications as described earlier [10]. The assay mixture was comprised of carboxymethylcellulose $(0.50 \%, \mathrm{pH} 7.0 ; 1 \mathrm{ml})$, enzyme (up to $100 \mu \mathrm{l}$ ), and volume was adjusted $2.0 \mathrm{ml}$ using $0.05 \mathrm{M}$ sodium phosphate buffer, $\mathrm{pH}$ 7.0. The reaction was allowed to progress by incubation at $50^{\circ} \mathrm{C}$ for $30 \mathrm{~min}$ in a water bath incubator followed by addition of $3 \mathrm{ml}$ of DNS reagent to stop the reaction. Thereafter, tubes were incubated in a boiling water bath for 5 min followed by cooling under running tap water. After that, optical density was determined at $575 \mathrm{~nm}$ using an ultraviolet-visible spectrophotometer. Glucose was used as a standard. Control tubes were also used simultaneously where enzyme was added after addition of DNS reagent. One unit of the enzyme activity was taken as the amount of the enzyme that liberated $1 \mu \mathrm{mol}$ of reducing sugars as glucose equivalent per minute under the conditions of enzyme assay. Protein estimation was carried out according to the procedure of Lowry et al. [12].

\subsection{OFAT Approach}

Two previously reported cellulase secreting bacteria, $B$. licheniformis and $O$. anthropi were used for the experiments [10].
On the basis of OFAT approaches, CMC liquid medium ingredients were altered to significantly enhance the cellulase activity. Different cellulose sources, namely, CMC, Whatman filter paper, rice bran, and wheat-straw at the concentration range of $1-5 \%$ were used individually as alternatives of carbon source in the medium to provide favorable conditions for the growth of bacteria and for maximum production of cellulase. Filter paper, rice bran, and wheatstraw were crushed to a mesh size of 5-10 mm using a pestle and mortar before use as a carbon source in the submerged fermentation medium. Various carbon sources with production media (CMC liquid media) were prepared and positive isolates were grown at $37^{\circ} \mathrm{C}$ in environmental orbital shaker at $150 \mathrm{rpm}$ speed. Cellulase activity was analyzed using cell free supernatant. The carbon source that gave maximum cellulase activity was taken as a viable substrate for analyses ahead.

To examine improvement in the secretion for cellulase, nitrogen sources, namely, ammonium sulfate, peptone, sodium nitrite, urea, and yeast extract at different concentrations ranging from 0.5 to $2 \%$ were used to supplement the submerged fermentation medium.

For $\mathrm{pH}$ optimization, submerged fermentation medium was used adjusted separately at $\mathrm{pH} 3.0,4.0,5.0,6.0,7.0,8.0,9.0$, and 10.0. For optimization of temperature, submerged fermentation medium was incubated at different temperatures, namely, $20^{\circ} \mathrm{C}, 30^{\circ} \mathrm{C}, 40^{\circ} \mathrm{C}$, $50^{\circ} \mathrm{C}, 60^{\circ} \mathrm{C}$, and $70^{\circ} \mathrm{C}$. For inoculum size, $0.1,0.5,1,1.5$, and $5 \%$ $\mathrm{v} / \mathrm{v}$ inocula were used in different sets. Multiple sets were employed and after calculation, average enzyme activity was used for analyses ahead.

\subsection{CCD and RSM}

The statistical experimental design, CCD was used to determine factors which affect enzyme secretion remarkably using software Design expert 8.1. The default central values chosen for the experimental design were $\mathrm{pH}(\mathrm{X} 1)$ 7; temperatures (X2) $45^{\circ} \mathrm{C}$, incubation period (X3) $36 \mathrm{~h}$, and inoculum size (X4) 1\% [Table 1]. Different combinations of the selected variables were calibrated according to the design in the medium containing $2 \% \mathrm{CMC}$ and $0.5 \%$ peptone as carbon and nitrogen sources, respectively [Table 2].

Table 1: Factor studied using the OFAT approach. One way ANOVA was used to study the effect of the variable on the production.

\begin{tabular}{llc} 
Variables & Range & $\begin{array}{c}\text { ANOVA (P-value) } \\
\text { Bacillus licheniformis; } \\
\text { Ochrobactrum anthropi }\end{array}$ \\
$\begin{array}{l}\text { Inoculum, \% } \\
\text { Temperature, }{ }^{\circ} \mathrm{C}\end{array}$ & $0.1-5$ & $0.15 ; 0.21$ \\
$\mathrm{pH}$ & $25-70$ & $0.1,0.11$ \\
Incubation time, h & $3-9$ & $0.2 ; 0.21$ \\
Nitrogen source & $24-96$ & $0.07 ; 0.1$ \\
& Ammonium sulfate & \\
& Urea & $0.04 * ; 0.61$ \\
Carbon source & Yeast extract & \\
& CMC & $0.035^{*} ; 0.42 *$ \\
& Filter-paper & \\
& Rice-bran & \\
\hline
\end{tabular}

*Indicates significant terms. OFAT: One factor at a time, CMC: Carboxymethyl cellulose, ANOVA: Analysis of variance 
The ranges of each of the variables are mentioned in Table 3. A total 36 experiments were performed in this study to identify the intensely affected variables for secretion of the enzyme. Three sets were prepared for each experimental run and average values were taken for analyses ahead. The second order non-linear polynomial equation used to fit the data is as follows [13]:

$$
Y=\beta \sum_{i=0}^{X_{4}} \text { Block }+S_{0}\left(X_{1}, X_{2}, X_{3}, X_{4}\right)
$$

Where $\mathrm{Y}$ is the enzyme activity (response); $\mathrm{X} 1$ to $\mathrm{X} 4$ are considered as the independent variables; $\beta$ is the model constant. Package RSM of "R for Statistical computing" was taken for the statistical analysis of experimental data and its response surface graph. The model generated was further examined for the robustness using analysis of variance (ANOVA). In general, model robustness was decided by Fisher's F-test, polynomial model conditions including coefficient of assurance and balanced.

To determine optimum conditions for carboxymethylcellulase production, RSM was employed with CCD [14]. An entirety of 36 experiments were conducted with three coded levels $(-1,0$, and +1$)$ [Table 2]. The experimental range of factors explored in this study is also summarized in Table 2. The cellulase activity response as yield in each primer was performed in duplicate. An "R" package, "RSM" was used for the experiment designing and followed analysis [14]. The assessment was performed to evaluate the response as a second order polynomial fit [15].

The software Design expert 8.0.1 was also employed for regression and graphical analyses of the data obtained to optimize cellulase production. The significance of the obtained model was performed using ANOVA function. The optimal value for the influencing parameters was obtained by the ridge analysis and analyzing the contour plots $[13,16]$. Threedimensional surface plots were attracted to show connection between the reactions and the test levels of every autonomous variable.

\subsection{Validation of the Predicted Model}

Based on the findings obtained during analysis, parameters were selected for validation of optimized medium model such as $\mathrm{pH}$, temperature, inoculum, incubation period, and these parameters were variable according to the designed model given by RSM. The rest of the components in the medium were unchanged and optimized medium was prepared. The composition of the broth medium was CMC $(0.5 \%)$, sodium nitrate $(0.1 \%)$, dipotassium hydrogen phosphate $(1 \%)$, potassium chloride $(0.1 \%)$, magnesium sulfate $(0.05 \%)$, and yeast extract $(0.05 \%)$. The predicted response surface model was also validated in triplicate.

\section{RESULTS AND DISCUSSION}

\subsection{OFAT Approach}

The secretion of the enzyme cellulase was optimized on the factors, namely, inoculum size, $\mathrm{pH}$, temperature, incubation period,

Table 2: Physiological parameters optimized in the study.

\begin{tabular}{lcccc} 
Variables & Unit & Symbol & Coded value +1 & Coded value -1 \\
Inoculum & $\% \mathrm{v} / \mathrm{v}$ & $\mathrm{X} 1$ & 0.1 & 5 \\
$\mathrm{pH}$ & - & $\mathrm{X} 2$ & 3.5 & 10.5 \\
Temperature & ${ }^{\circ} \mathrm{C}$ & $\mathrm{X} 3$ & 25 & 55 \\
Incubation time & Hours & $\mathrm{X} 4$ & 24 & 72 \\
\hline
\end{tabular}

nitrogen source, and carbon source as described by Lugani et al. [17]. For this analysis, there were five sources of carbon and nitrogen each investigated for higher cellulase production. The results are shown in Figure 1a and 2a. It was found that maximum cellulase production was at the rate of $102.1 \pm 10.72 \mu \mathrm{M} / \mathrm{min} / \mathrm{mg}$ for $B$. licheniformis and at the rate of $74.5 \pm 7.67 \mu \mathrm{M} / \mathrm{min} / \mathrm{mg}$ for $O$. anthropi was at $1 \%$ inoculum amount. Shankar et al. [18] reported maximum production of cellulase at $2 \%$ inoculum size for Bacillus pumilus.

Here,maximumenzymeproductionattherateof $98.4 \pm 10.23 \mu \mathrm{M} / \mathrm{min} / \mathrm{mg}$ was observed in case of $B$. licheniformis when $\mathrm{pH}$ of the growth medium was $\mathrm{pH} 7.0$ [Figure 1b]. The strain, O. anthropi showed maximum cellulase production at the rate of $62.1 \pm 6.41 \mu \mathrm{M} / \mathrm{min} / \mathrm{mg}$ at $\mathrm{pH} 8.0$ [Figure 2b]. However, other researchers reported $\mathrm{pH} 6.5$ for maximum cellulase production for $O$. anthropi $[13,19]$.

Both $B$. licheniformis and $O$. anthropi showed maximum cellulase production at the rate of $48.1 \pm 4.85 \mu \mathrm{M} / \mathrm{min} / \mathrm{mg}$ and $69.5 \pm$ $7.15 \mu \mathrm{M} / \mathrm{min} / \mathrm{mg}$, respectively at $40^{\circ} \mathrm{C}$ [Figure $1 \mathrm{c}$ and $\left.2 \mathrm{c}\right]$. Other reports also showed optimum temperature of $40^{\circ} \mathrm{C}$ with $B$. licheniformis, Bacillus subtilis, Serratia marcescens, Pseudomonas fluorescens and Escherichia coli $[11,13]$. It is considered that upon further increase in temperature increase led to loss of enzyme activity due to temperature impact enzyme denaturation was observed [17].

For optimization of incubation period for enzyme secretion, both the bacterial strains separately were incubated for different time periods ranging from $24 \mathrm{~h}$ to $124 \mathrm{~h}$. The results are shown in Figure 1d and $2 \mathrm{~d}$. The data showed that maximum enzyme secretion at the rate of $103.5 \pm 10.86 \mu \mathrm{M} / \mathrm{min} / \mathrm{mg}$ in case of B. licheniformis, and $74.5 \pm$ $7.67 \mu \mathrm{M} / \mathrm{min} / \mathrm{mg}$ in case of $O$. anthropi was after $72 \mathrm{~h}$ incubation. Shankar et al. [18] showed maximum cellulase secretion by $B$. pumilus after $72 \mathrm{~h}$ incubation. However, Duza et al. [20] showed maximum cellulase secretion after $96 \mathrm{~h}$ incubation in case of $O$. anthropi.

The correlation of various nitrogen sources on cellulase secretion was studied keeping peptone in the medium and also replacing it with different nitrogen sources, namely, ammonium sulfate, sodium nitrite, urea, and yeast extract at the amounts between 0.5 and $2 \%$ in the growth medium. Out of all the nitrogen sources tested, $0.5 \%$ peptone was observed to be the best for cellulase secretion. As shown in Figure 1e and 2e, B. licheniformis secreted cellulase at the rate of 101 $\pm 10.30 \mu \mathrm{M} / \mathrm{min} / \mathrm{mg}$ and $O$. anthropi at the rate of $63.2 \pm 7.67 \mu \mathrm{M} / \mathrm{min} /$ $\mathrm{mg}$ with peptone as nitrogen source. Ray et al. [21] showed maximum cellulase secretion by B. subtilis CY5 and Bacillus circulans TP3 in the presence of $0.5 \%$ peptone in the culture medium. Duza et al. [20] showed maximum cellulase secretion by $O$. anthropi with $1.0 \%$ tryptone in the culture medium.

Among various carbon sources, $2 \% \mathrm{CMC}$ was found to be the better carbon source among tested sources for cellulase secretion. The data are shown in Figure $1 \mathrm{f}$ for $B$. licheniformis where rate of cellulase production was found to be $108.2 \pm 10.82 \mu \mathrm{M} / \mathrm{min} /$ $\mathrm{mg}$. For $O$. anthropi, data are reported in Figure $2 \mathrm{f}$ where rate of cellulase production was $69.5 \pm 7.15 \mu \mathrm{M} / \mathrm{min} / \mathrm{mg}$. There are reports indicating $1 \% \mathrm{CMC}$ in the medium was optimum for secretion of cellulase [17].

\subsection{CCD and RSM}

The significant influential variables for cellulase production are mentioned in Table 1. All the runs were performed in triplicate and 
Table 3: Summary of CCD design prepared by RSM and their respective responses by the studied microorganisms.

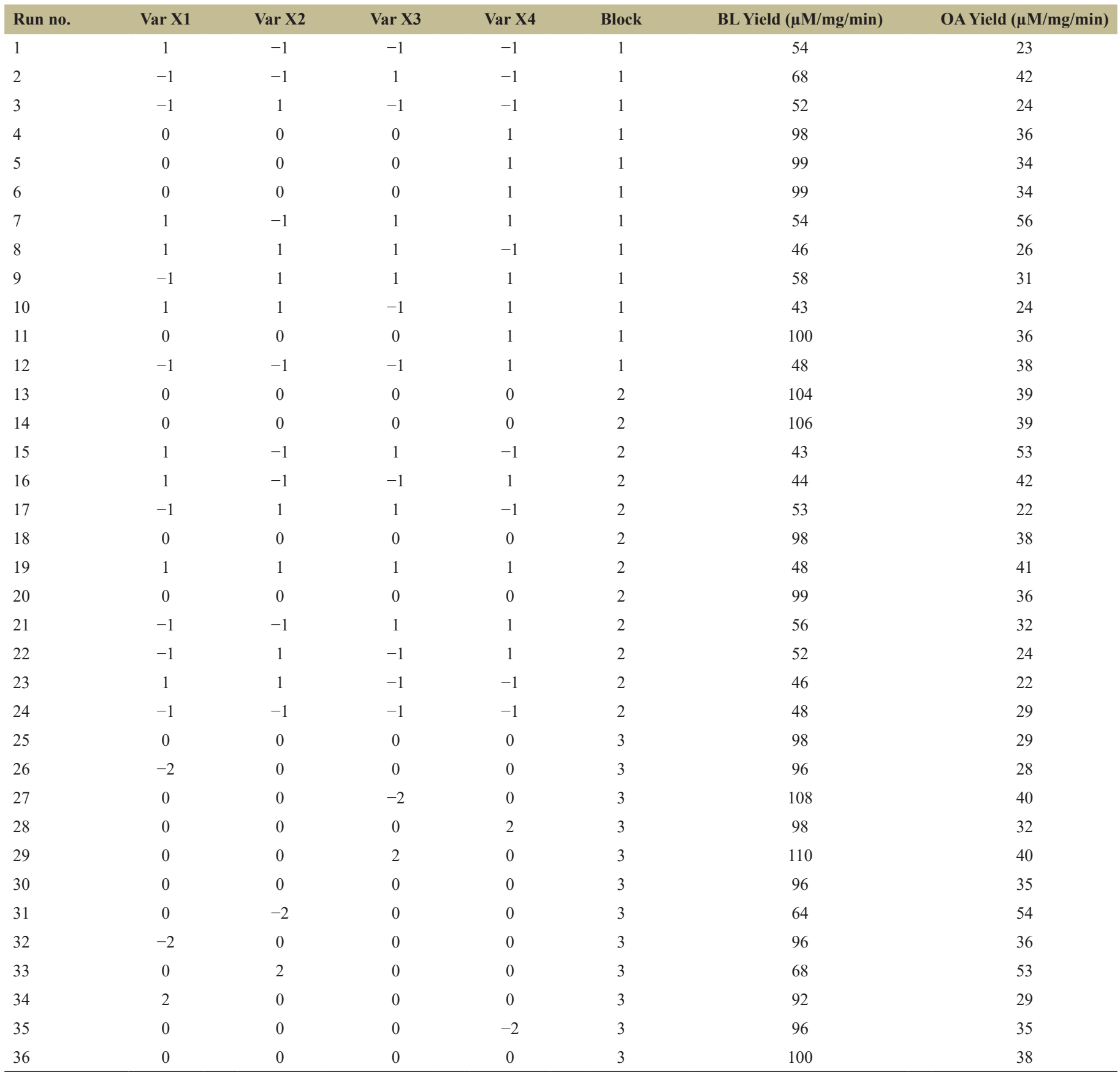

BL: Bacillus licheniformis, OA: Ochrobactrum anthropi, CCD: Central composite design, RSM: Response surface methodology

average values were taken. The CCD design was composed of 36 runs and the respective cellulase activities are specified in Table 3. Four different key production modulator factors, namely, inoculum size, $\mathrm{pH}$, incubation period, and temperature were selected by OFAT method. Further optimization experiments were performed selecting most effective variables and developed models were analyzed further for fluctuations using ANOVA.

The correlation coefficient $\left(\mathrm{R}^{\wedge} 2\right)$ value defines the correlation between experimental and the predicted values obtained by the developed model. The values of our model were 0.90 indicating a high degree of correlation between the calculated and experimentally determined production values. On analysis of response surface curves, optimal conditions were found to be $\mathrm{X} 1: 1.8 \%, \mathrm{X} 2: 40^{\circ} \mathrm{C}, \mathrm{X} 3: 6.5$, and $\mathrm{X} 4: 72 \mathrm{~h}$ for B. licheniformis; and $\mathrm{X} 1: 3 \%, \mathrm{X} 2: 35^{\circ} \mathrm{C}, \mathrm{X} 3: 8.0$, and $\mathrm{X} 4: 72 \mathrm{~h}$ for $O$. anthropi, respectively. The theoretical and experimentally determined production at the given conditions has been summarized in Table 4. The mean difference between calculated and observed production value was non-significant. Therefore, the models were assets as highly correlated.

Non-linear quadratic polynomial equations (1) and (2) are for $B$. licheniformis and $O$. anthropi respectively. The relationship between studied parameters and robustness of the model are summarized in Tables 3 and 4 for two models generated using $B$. licheniformis and $O$. 


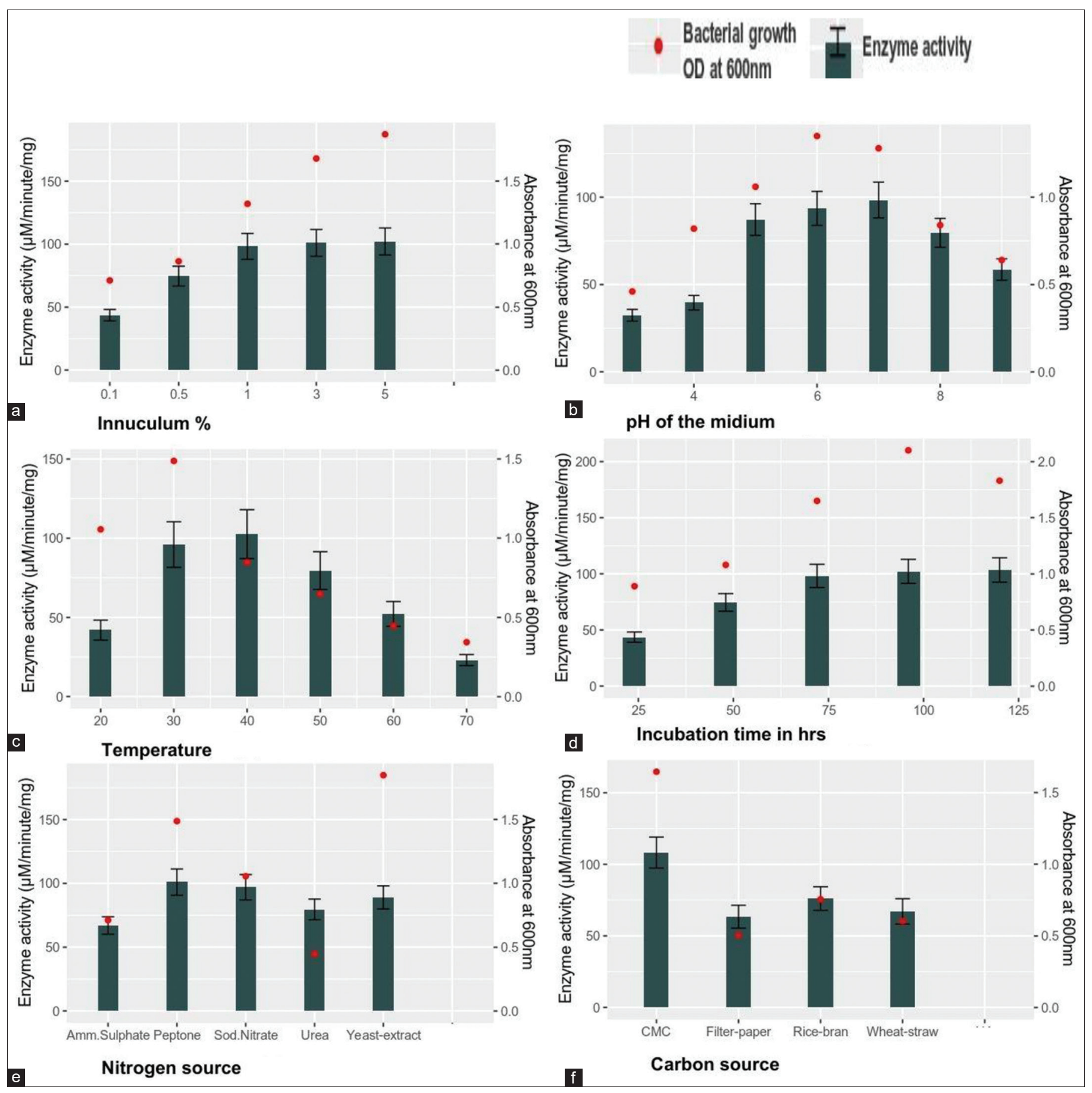

Figure 1: Effect of various variables on the cellulase production. one factor at a time approach was used to analyze the influence of (a) inoculums percentage (b) $\mathrm{pH}$ (c) temperature (d) incubation time (e) nitrogen source (f) carbon source on the Bacillus licheniformis. In the figure, the bar represents cellulase production and red-dot represents growth as optical density in the respective parameters.

anthropi, respectively. A quadratic nonlinear polynomial equation was developed based on the independent variables in terms of actual values and the experimental results.

$$
\begin{aligned}
& Y_{(\text {B.lichenoformis })}=-2.79 X_{1}-0.37 X_{2}+1.7 X_{3}-0.12 X_{4} \\
& -0.31 X_{1} X_{2}-1.93 X_{1} X_{3}+0.5 X_{1} X_{4}-0.81 X_{2} X_{3} \\
& +0.93 X_{2} X_{4}-8.23 X_{1}^{2}-15.2 X_{2}^{2}-4.48 X_{3}^{2}-7.48 X_{4}^{2}
\end{aligned}
$$

$$
\begin{aligned}
& Y_{(\text {O.anthropi })}=+1.95 X_{1}-4.29 X_{2}+3.20 X_{3}+1.70 X_{4}-1.31 X_{1} X_{2} \\
& +3.31 X_{1} X_{3}+1.93 X_{1} X_{4}-1.56 X_{2} X_{3}+0.31 X_{2} X_{4} \\
& -0.81 X_{3} X_{4}-2.80 X_{1}^{2}+3.44 X_{2}^{2}+0.07 X_{3}^{2}-1.55 X_{4}^{2}
\end{aligned}
$$

The higher F-value 9.41 and 9.81 for the models using $B$. licheniformis and $O$. anthropi, respectively, and lower probability $(P<0.05$ at $95 \%$ certainty level) demonstrated that these models were significant [Tables 


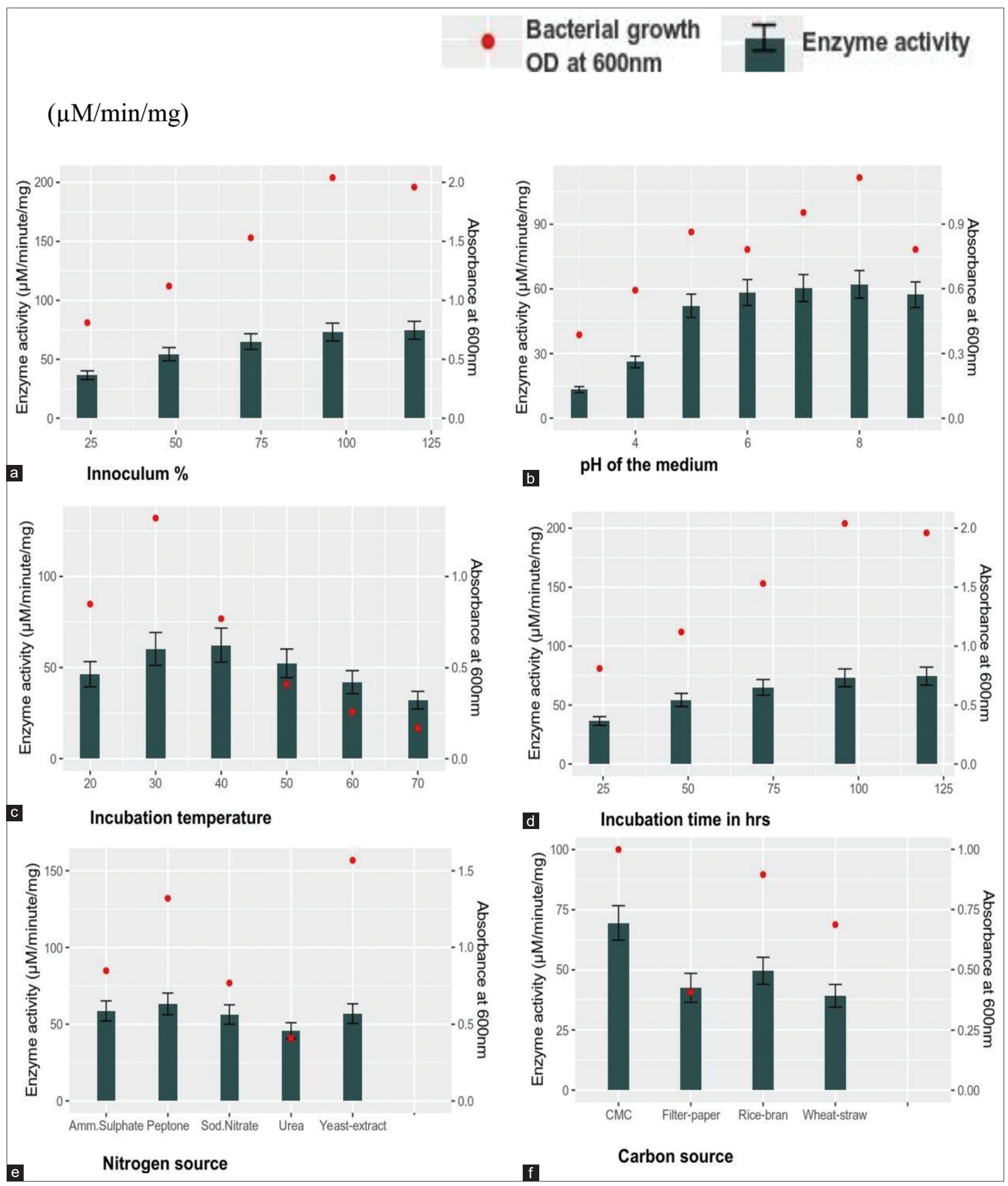

Figure 2: Different variables and cellulase production $(\mu \mathrm{M} / \mathrm{min} / \mathrm{mg})$ relationship: One factor at a time approach was used to analyze the effect of (a) inoculums percentage (b) $\mathrm{pH}$ (c) temperature (d) incubation time (e) nitrogen source (f) carbon source on the Ochrobactrum anthropi. In the figure, the bar represents cellulase production and red-dot represents growth as optical density in the respective parameters. 
5 and 6]. The F-values and probability for all the individual, interaction, and square terms of the variables vary from high to low showing that all the individual, interaction, and square effects of each variable differ from each other. In addition, a non-significant lack of fit value showed that the model looks to be good and may be used for the predictions.
Three-dimensional response plots were also useful to visualize the influence of various studied parameters on the mass secretion of cellulase [Figures 3 and 4]. In these illustrations, cellulase activity was plotted on the z-axis against any two parameters keeping other variables constant (at central level). Further

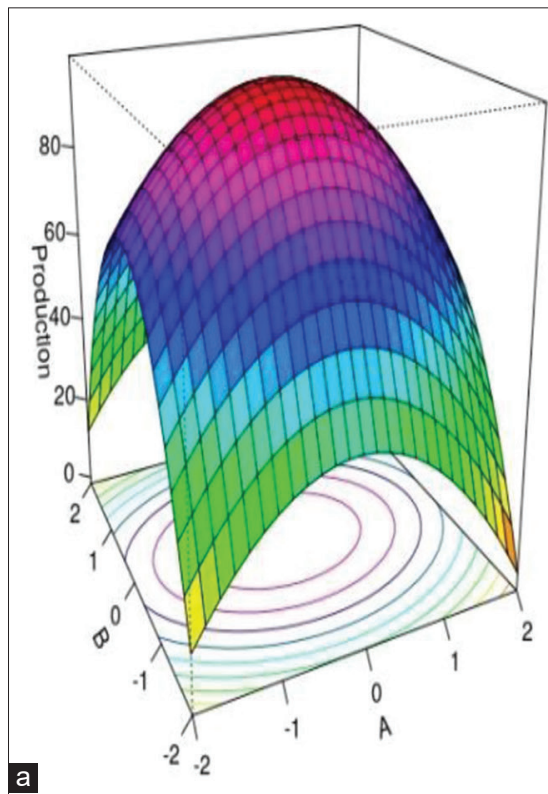

Sllce at $B \| k=2, C=0, D=0$

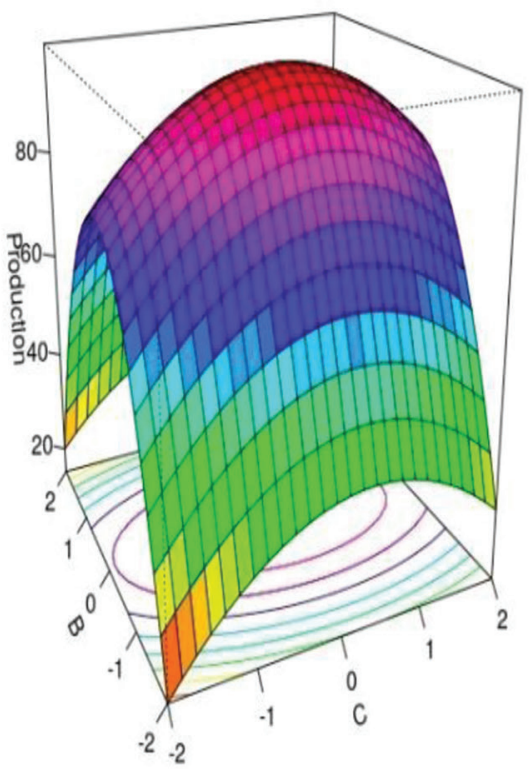

d

Figure 3: (a-f) Three-dimensional plot of the responses as yielded by Bacillus licheniformis on various physiological conditions. Here A, B, C, and D represent inoculums, temperature, $\mathrm{pH}$, and incubation period, respectively. Figure heads $\mathrm{A}$ to $\mathrm{F}$ represent the possible combinations of the studied parameters, namely, $\mathrm{AB}$,

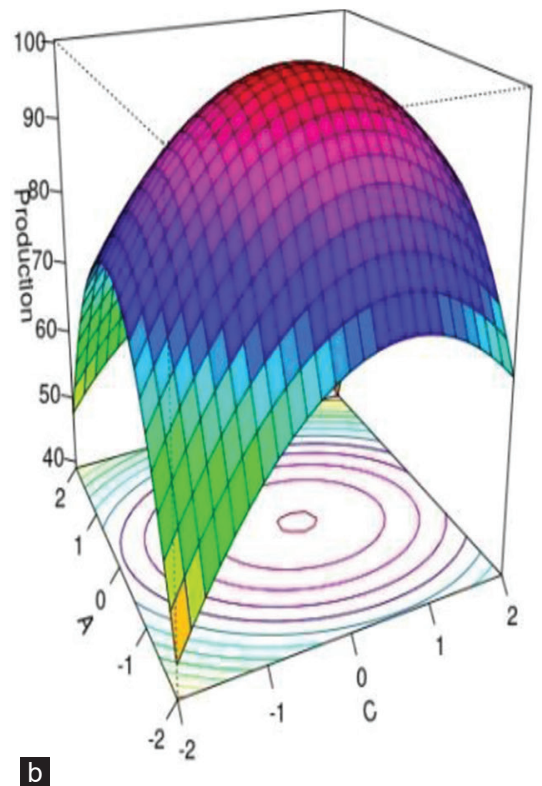

Sllce at $B \| k=2, B=0, D=0$

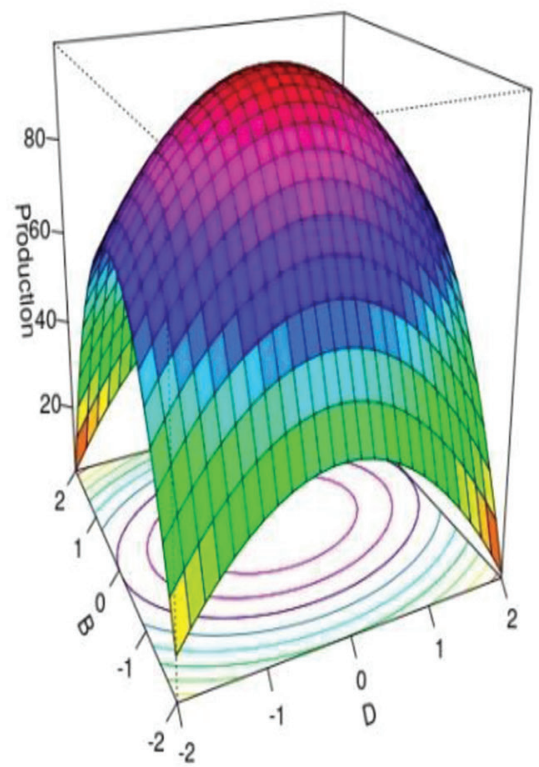

Sllce at $B \| k=2, A=0, C=0$

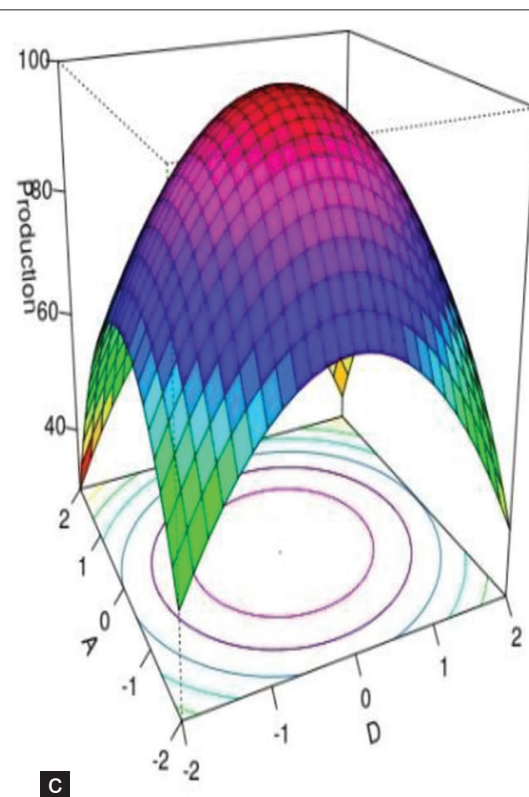

Slice at $B \| k=2, B=0, C=0$

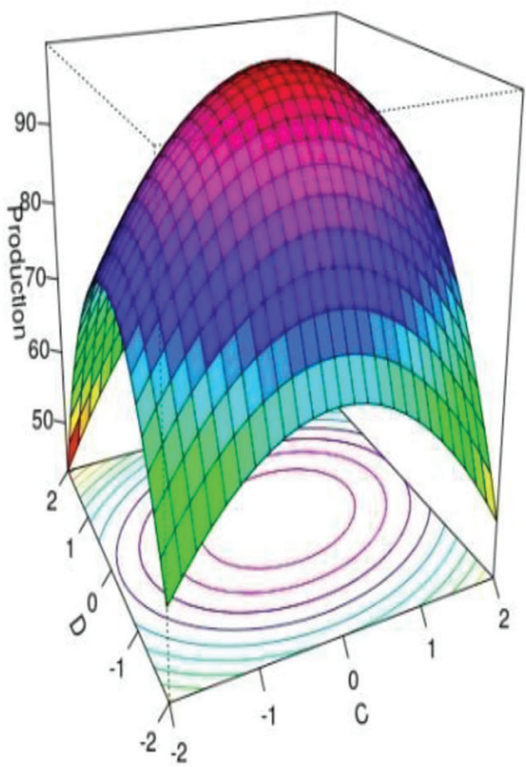

Sllce at $B \| k=2, A=0, B=0$ 


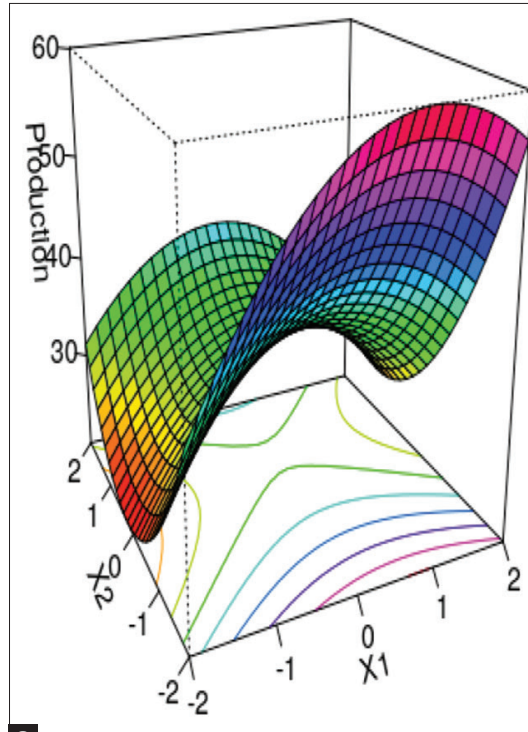

a

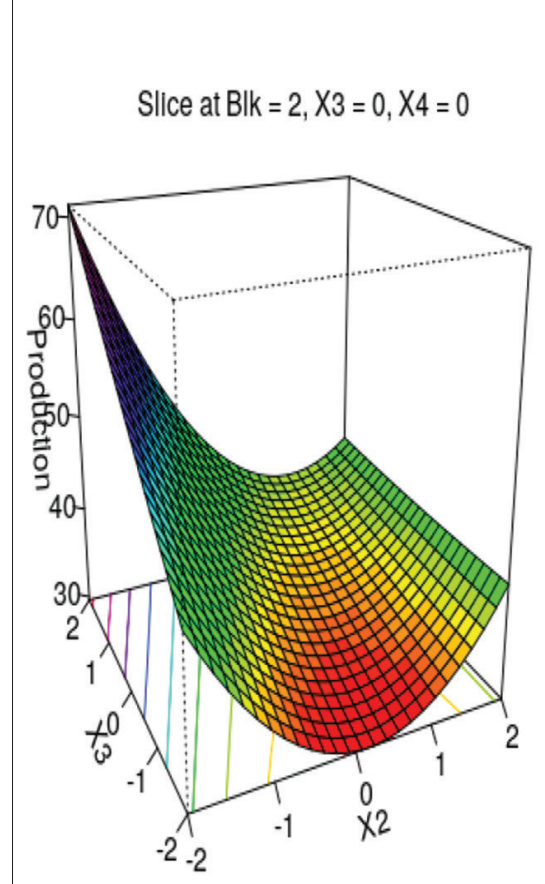

Slice at $B \mid k=2, X 1=0, X 4=0$

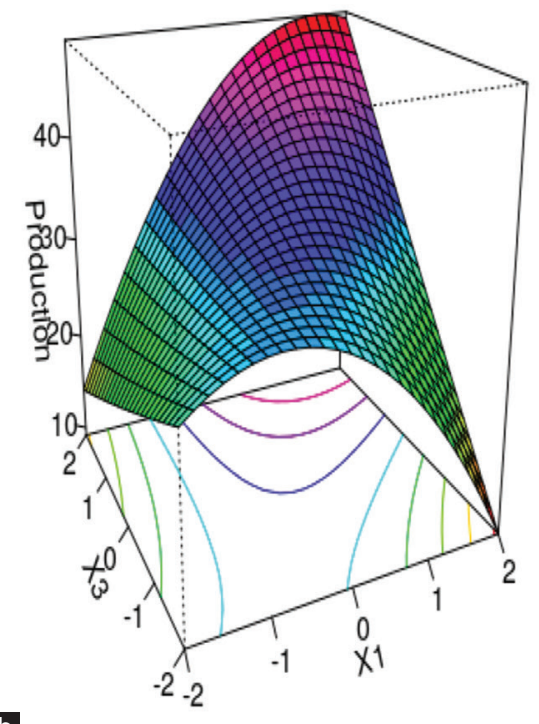

b

$$
\text { Slice at } B \mid k=2, X_{2}=0, X 4=0
$$

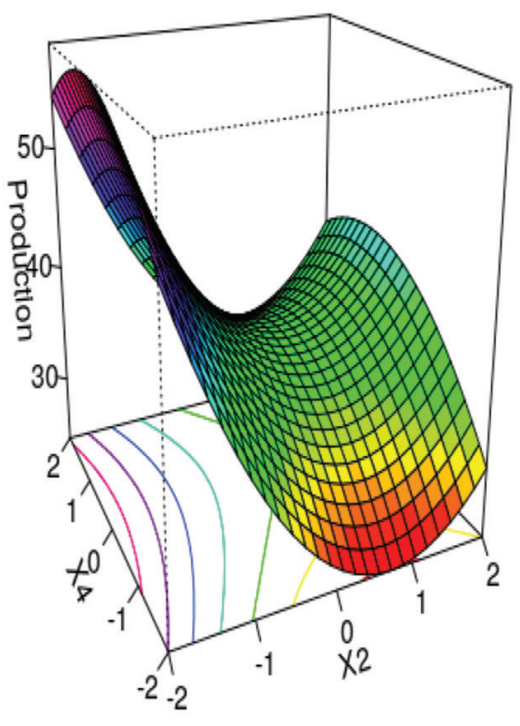

Slice at $B \mid k=2, X_{1}=0, X_{3}=0$

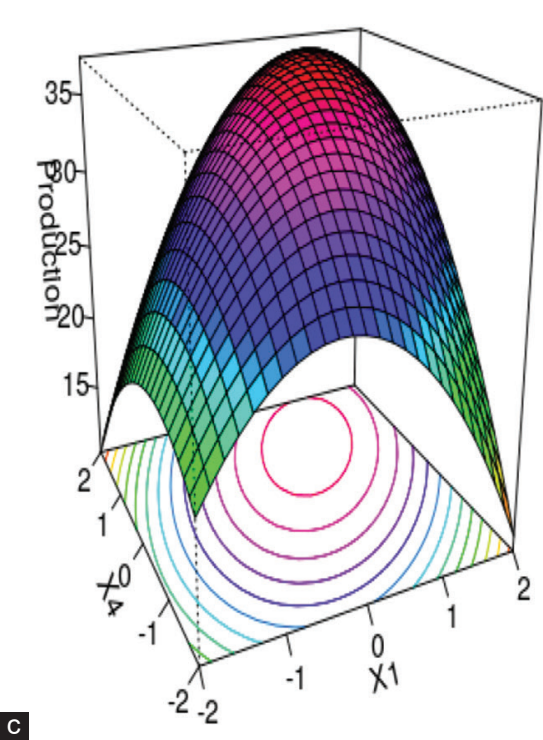

Slice at $B \mid k=2, X 2=0, X 3=0$

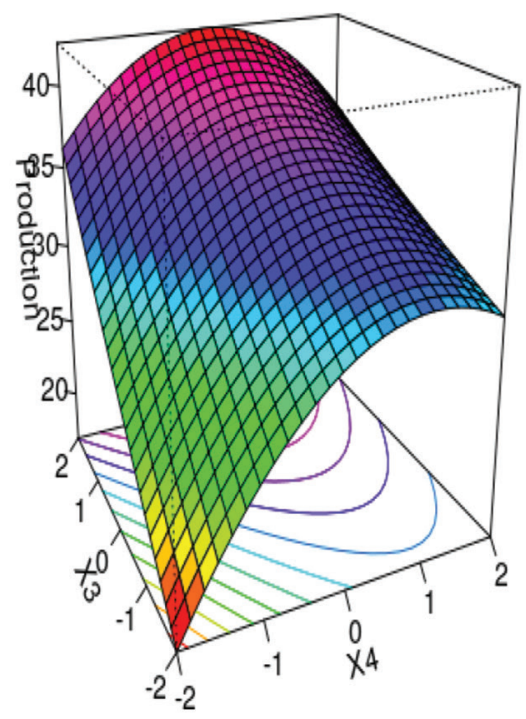

Slice at $B \mid k=2, X 1=0, X_{2}=0$

Figure 4: (a-f) Three-dimensional plot of the responses as yielded by Ochrobactrum anthropi on various physiological conditions. Here X1, X2, X3, and X4 represent inoculums, temperature, $\mathrm{pH}$, and incubation period, respectively. Figure heads A to F represent the possible combinations of the studied parameters, namely, X1X2, X1X3, X1X4, X2X3, X2X4, and X3X4, respectively.

production was carried out to confirm the optimized conditions as predicted using the models. Production was carried out for $72 \mathrm{~h}$ at optimized conditions [Table 4]. The maximum cellulase activity was calculated to be $118 \mu \mathrm{M} / \mathrm{mg} / \mathrm{mL}$ and $69 \mu \mathrm{M} / \mathrm{mg} / \mathrm{mL}$ for $B$. licheniformis and $O$. anthropi, respectively. This justified RSM- predicted cellulase activity and optimized media by RSM yielded the highest observed cellulase activity so far reported [13,22-25]. Results also indicated that $B$. licheniformis and $O$. anthropi are viable cellulase producers for use of the enzyme in industrial applications $[13,20]$. 


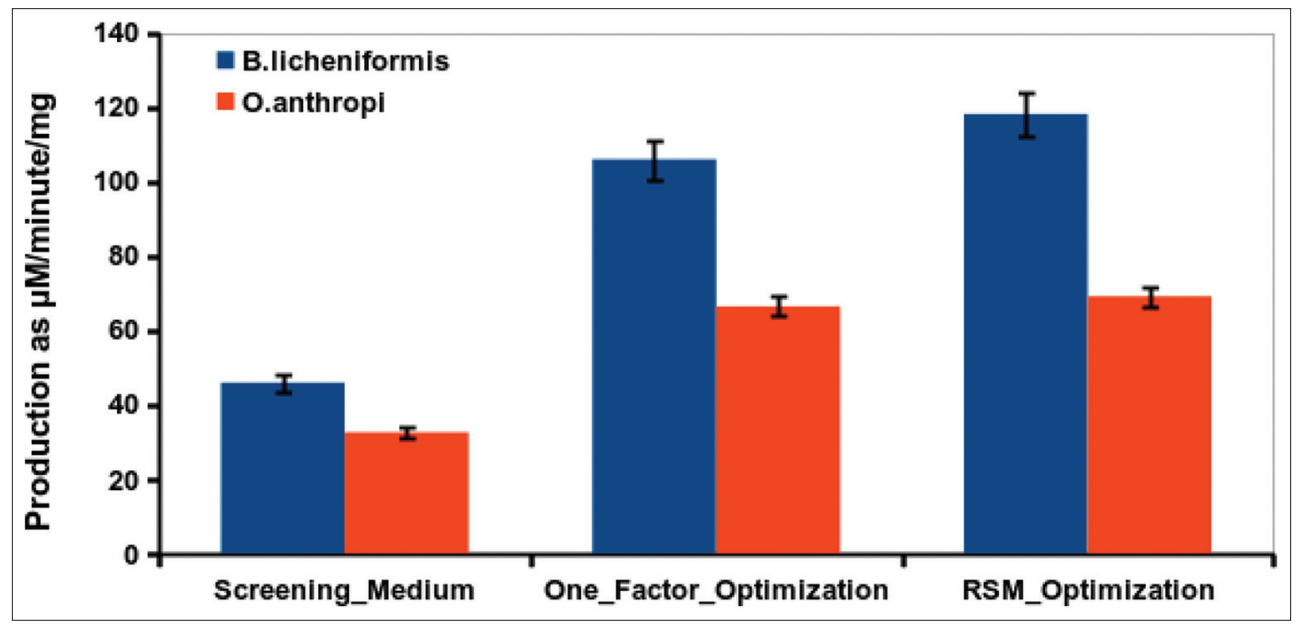

Figure 5: Relative values on the production of cellulase by Bacillus licheniformis and Ochrobactrum anthropi under unoptimized conditions (screening medium), one factor optimized, and RSM optimized medium.

Table 4: Post-optimization validations of the mathematical models.

\begin{tabular}{lccc} 
Microorganisms & Parameters & $\begin{array}{c}\text { Expected } \\
\text { production }\end{array}$ & Actual production \\
Bacillus & $\mathrm{X} 1: 1.8 \%$ & 124 & $118 \pm 12 \mu \mathrm{M} / \mathrm{min} / \mathrm{mg}$ \\
licheniformis & $\mathrm{X} 2: 40^{\circ} \mathrm{C}$ & $\mu \mathrm{M} / \mathrm{min} / \mathrm{mg}$ & \\
& $\mathrm{X} 3: 6.5$ & & \\
& $\mathrm{X} 4: 72 \mathrm{~h}$ & & \\
& $\mathrm{X} 1: 3 \%$ & 82.3 & $69.3 \pm 8.5 \mu \mathrm{M} / \mathrm{min} / \mathrm{mg}$ \\
Ochrobactrum & $\mathrm{X} 2: 35^{\circ} \mathrm{C}$ & $\mu \mathrm{M} / \mathrm{min} / \mathrm{mg}$ & \\
anthropi & $\mathrm{X} 3: 8.0$ & & \\
& $\mathrm{X} 4: 72 \mathrm{~h}$ & & \\
\hline
\end{tabular}

Table 5: Analysis of variance (CCD response variable) for cellulase production using $B$. licheniformis $(\mu \mathrm{M} / \mathrm{min} / \mathrm{mg})$.

\begin{tabular}{|c|c|c|c|c|}
\hline Source & Estimate & Std error & $t$-value & $\operatorname{Prob}>|t|$ \\
\hline Model & 74.16 & 8.1 & 9.14 & $>0.001 *$ \\
\hline $\mathrm{X} 1$ & -2.79 & 3.3 & -0.84 & 0.4 \\
\hline $\mathrm{X} 2$ & -0.37 & 3.3 & -0.11 & 0.91 \\
\hline $\mathrm{X} 3$ & 1.7 & 3.3 & 0.51 & 0.61 \\
\hline $\mathrm{X} 4$ & -0.12 & 3.3 & -0.03 & 0.97 \\
\hline $\mathrm{X} 1: \mathrm{X} 2$ & -0.31 & 4.05 & -0.07 & 0.93 \\
\hline $\mathrm{X} 1: \mathrm{X} 3$ & -1.93 & 4.05 & -0.47 & 0.63 \\
\hline $\mathrm{X} 1: \mathrm{X} 4$ & 0.56 & 4.05 & 0.13 & 0.83 \\
\hline $\mathrm{X} 2: \mathrm{X} 3$ & -0.81 & 4.05 & -0.2 & 0.84 \\
\hline $\mathrm{X} 2: \mathrm{X} 4$ & 0.93 & 4.05 & 0.23 & 0.81 \\
\hline $\mathrm{X} 3: \mathrm{X} 4$ & 1.31 & 4.05 & 0.32 & 0.74 \\
\hline $\mathrm{X} 1^{2}$ & -8.23 & 2.8 & -2.87 & $0.009 *$ \\
\hline $\mathrm{X} 2^{2}$ & -15.23 & 2.8 & -5.31 & $>0.001 *$ \\
\hline $\mathrm{X} 3^{2}$ & -4.48 & 2.8 & -1.56 & 0.13 \\
\hline \multirow[t]{2}{*}{$\mathrm{X} 4^{2}$} & -7.48 & 2.8 & -2.61 & $0.01 *$ \\
\hline & Df & Mean & F-value & Prob $>$ F \\
\hline Residuals & 20 & 262.8 & & \\
\hline Lack of fit & 10 & 516.6 & 59.05 & $>0.001 *$ \\
\hline Pure error & 10 & 8.8 & & \\
\hline
\end{tabular}

*Indicates significant terms. CCD: Central composite design
Table 6: Analysis of variance (CCD response variable) for cellulase production using Ochrobactrum anthropi $(\mu \mathrm{M} / \mathrm{min} / \mathrm{mg})$.

\begin{tabular}{|c|c|c|c|c|}
\hline Source & Estimate & Std error & $t$-value & Prob $>\mid t$ \\
\hline Model & 32.08 & 3.2 & 9.81 & $>0.001^{*}$ \\
\hline $\mathrm{X} 1$ & 1.81 & 1.3 & 1.4 & 0.17 \\
\hline $\mathrm{X} 2$ & -4.29 & 1.3 & -3.21 & $0.004 *$ \\
\hline $\mathrm{X} 3$ & 3.2 & 1.3 & 2.4 & $0.025^{*}$ \\
\hline $\mathrm{X} 4$ & 1.7 & 1.3 & 1.28 & 0.21 \\
\hline $\mathrm{X} 1: \mathrm{X} 2$ & -1.31 & 1.6 & -0.8 & 0.43 \\
\hline $\mathrm{X} 1: \mathrm{X} 3$ & 3.31 & 1.6 & 2.02 & 0.05 \\
\hline $\mathrm{X} 1: \mathrm{X} 4$ & 1.93 & 1.6 & 1.18 & 0.25 \\
\hline $\mathrm{X} 2: \mathrm{X} 3$ & -1.56 & 1.6 & -0.95 & 0.35 \\
\hline $\mathrm{X} 2: \mathrm{X} 4$ & 0.31 & 1.6 & 0.19 & 0.85 \\
\hline $\mathrm{X} 3: \mathrm{X} 4$ & -0.81 & 1.6 & -0.49 & 0.62 \\
\hline $\mathrm{X} 1^{2}$ & -2.8 & 1.1 & -2.4 & $0.025^{*}$ \\
\hline$X 2^{2}$ & 3.44 & 1.1 & 2.98 & $>0.007^{*}$ \\
\hline$X 3^{2}$ & 0.07 & 1.1 & 0.06 & 0.95 \\
\hline & -1.55 & 1.1 & -1.3 & 0.19 \\
\hline & Df & Mean & F-value & Prob $>$ F \\
\hline Residuals & 20 & 42.7 & & \\
\hline Lack of fit & 10 & 77.12 & 1.27 & $0.18 * *$ \\
\hline Pure error & 10 & 8.32 & & \\
\hline
\end{tabular}

\subsection{Validation of the Predicted Model}

The predicted model was evaluated with the use of chosen factors for the optimization process independent variables such as $\mathrm{pH}$, temperature, inoculum percentage, and incubation period. Higher cellulase secretion was observed in B. licheniformis and predicted by RSM as $124 \mu \mathrm{M} / \mathrm{min} / \mathrm{mg}$. In case of $O$. anthropi, cellulase secretion was observed to be $82.3 \mu \mathrm{M} / \mathrm{min} / \mathrm{mg}$ as expected production by RSM [Table 4].

Cellulase secretion was also tested with 11 flask level using parameters of $250 \mathrm{~mL}$ optimized RSM medium and cellulase activity. It gave 118 $\pm 12 \mu \mathrm{M} / \mathrm{min} / \mathrm{mg}$ and $69.3 \pm 8.5 \mu \mathrm{M} / \mathrm{min} / \mathrm{mg}$ for $B$. licheniformis and $O$. anthropi, respectively. Relative analysis of cellulase production 
is shown in Figure 5. Other researchers also authenticated cellulase production after predicting by RSM [26].

\section{CONCLUSION}

The enzyme cellulase is much industrially significant enzyme used in various commercial applications such as ethanol production for biofuel, paper/pulp manufacturing, food processing, textile refining, and beverages production. Bacteria, B. licheniformis and $O$. anthropi which were earlier isolated and shown to be cellulase producing bacteria in our laboratory were employed here for sub-merged fermentation. Various variables, namely, incubation period, inoculum size, temperature, and $\mathrm{pH}$ were optimized using OFAT approach and RSM based CCD was used for experimental validation. The optimization model using OFAT and RSM enhanced the cellulase activity by 2.5 fold in both $B$. licheniformis and $O$. anthropi optimized media conditions as against unoptimized basal media. Both these bacteria are good candidates for cellulase production under sub-merged conditions.

\section{ACKNOWLEDGMENTS}

The facilities of the Department of Biotechnology, Government of India, New Delhi (DBT) present in our School under the M.Sc. Biotechnology program, and Bioinformatics Sub Centre are gratefully acknowledged.

\section{CONFLICTS OF INTEREST}

Authors declared that they do not have any conflicts of interest.

\section{AUTHOR CONTRIBUTIONS}

All authors made substantial contributions to conception and design, acquisition of data, or analysis and interpretation of data; took part in drafting the article or revising it critically for important intellectual content; agreed to submit to the current journal; gave final approval of the version to be published; and agree to be accountable for all aspects of the work. All the authors are eligible to be an author as per the international committee of medical journal editors (ICMJE) requirements/guidelines.

\section{FUNDING}

There is no funding to report.

\section{ETHICAL APPROVALS}

This study does not involve experiments on animals or human subjects.

\section{PUBLISHER'S NOTE}

This journal remains neutral with regard to jurisdictional claims in published institutional affiliation.

\section{REFERENCES}

1. Hall M, Bansal P, Lee JH, Realff MJ, Bommarius AS. Cellulose crystallinity-a key predictor of the enzymatic hydrolysis rate. FEBS J 2010;277:1571-82.

2. Marco ÉG, Heck K, Martos ET, Van Der Sand ST. Purification and characterization of a thermostable alkaline cellulase produced by Bacillus licheniformis 380 isolated from compost. Anais Acad Bras Ciên 2017;89:2359-70.

3. Cai Y, Huang Y, Huang X, Fan Z, Yu T. Efficient biodegradation of organic matter using a thermophilic bacterium and development of a cost-effective culture medium for industrial use. J Environ Sci Health Part A 2020;55:686-96.

4. Jampana SR, Jia L, Ramarao BV, Kumar D. Experimental investigation of the adsorption and desorption of cellulase enzymes on zeolite- $\beta$ for enzyme recycling applications. Bioproc Biosyst Eng 2020;16:1.

5. Yang ST, El-Ensashy H, Thongchul N. In Bioprocessing Technologies in Biorefinery for Sustainable Production of Fuels, Chemicals, and Polymers. United States: John Wiley \& Sons; 2013.

6. Premalatha N, Gopal NO, Jose PA, Anandham R, Kwon SW. Optimization of cellulase production by Enhydrobacter sp. ACCA2 and its application in biomass saccharification. Front Microbiol 2015;6:1046.

7. Bhagwat S, Girma AD, Kumar A. Statistical optimization of enzymatic saccharification of acid pre-treated Parthenium hysterophorus biomass using response surface methodology. Biofuels 2016;7:501-9.

8. Rastogi G, Muppidi GL, Gurram RN, Adhikari A, Bischoff KM, Hughes SR, et al. Isolation and characterization of cellulosedegrading bacteria from the deep subsurface of the Homestake gold mine, Lead, South Dakota, USA. J Ind Microbiol Biotechnol 2009;36:585-98.

9. Mudgil D, Barak S, Khatkar BS. Optimization of enzymatic hydrolysis of guar gum using response surface methodology. J Food Sci Technol 2014;51:1600-5.

10. Maravi P, Kumar A. Isolation, screening and identification of cellulolytic Bacteria from soil. Biotechnol J Int 2020;24:1-8.

11. Sethi S, Datta A, Gupta BL, Gupta S. Optimization of cellulase production from Bacteria isolated from soil. ISRN Biotechnol 2013;2013:985685.

12. Lowry OH, Rosebrough NJ, Farr AL, Randall RJ. Protein measurement with the Folin phenol reagent. J Biol Chem 1951;193:265-75.

13. Shajahan S, Moorthy IG, Sivakumar N, Selvakumar G. Statistical modeling and optimization of cellulase production by Bacillus licheniformis NCIM 5556 isolated from the hot spring, Maharashtra, India. J King Saudi Univ Sci 2017;29:302-10.

14. Lenth RV. Response-surface methods in R, using rsm. J Stat Soft 2009;32:1-7.

15. Wang Y, Fang X, An F, Wang G, Zhang X. Improvement of antibiotic activity of Xenorhabdus bovienii by medium optimization using response surface methodology. Microb Cell Fact 2011;10:98.

16. Singh J, Kaur P. Optimization of process parameters for cellulase production from Bacillus sp. JS14 in solid substrate fermentation using response surface methodology. Braz Arch Biol Technol 2012;55:505-12.

17. Lugani Y, Singla R, Sooch BS. Optimization of cellulase production from newly isolated Bacillus sp. Y3. J Bioproc Biotech 2015;5:1.

18. Shankar T, Isaiarasu L. Cellulase production by Bacillus pumilus EWBCM1 under varying cultural conditions. Middle East J Sci Res 2011;8:40-5.

19. Acharya S, Chaudhary A. Optimization of fermentation conditions for cellulases production by Bacillus licheniformis MVS1 and Bacillus sp. MVS3 isolated from Indian hot spring. Braz Arch Biol Technol 2012;55:497-503.

20. Duza MB, Mastan SA. Optimization studies on cellulase production from Bacillus anthracis and Ochrobactrum anthropic (YZ1) isolated from soil. Int J Appl Sci Biotechnol 2015;3:272-84.

21. Ray AK, Bairagi A, Ghosh KS, Sen SK. Optimization of fermentation conditions for cellulase production by Bacillus subtilis CY 5 and TP3 isolated from fish gut. Acta Ichthyol Piscat 2007;1:47-53.

22. Thakkar A, Saraf M. Application of statistically based experimental designs to optimize cellulase production and identification of gene. Natl Prod Bioprospect 2014;4:341-51.

23. Rashid SS, Alam MZ, Karim MI, Salleh MH. Optimization of the 
nutrient supplements for cellulase production with the basal medium palm oil mill effluent. World Acad Sci Eng Technol 2009;60:809-15.

24. Saravanan P, Muthuvelayudham R, Viruthagiri T. Application of statistical design for the production of cellulase by Trichoderma reesei using mango peel. Enzyme Res 2012;2012:157643.

25. Dave BR, Parmar P, Sudhir A, Panchal K, Subramanian RB. Optimization of process parameters for cellulase production by Bacillus licheniformis MTCC 429 using RSM and molecular characterization of cellulase gene. J Bioproc Biotech 2015;5:1000212.

26. Ahmad T, Sharma A, Gupta G, Mansoor S, Jan S, Kaur B, et al.
Response surface optimization of cellulase production from Aneurinibacillus aneurinilyticus BKT-9: An isolate of urban Himalayan freshwater. Saudi J Biol Sci 2020;27:2333-43.

How to cite this article:

Maravi P, Kumar A. Optimization and statistical modeling of microbial cellulase production using submerged culture. J App Biol Biotech. 2021; 9(2):142-152. DOI: $10.7324 / J A B B .2021 .9213$ 